\title{
Exploration of Students’ Misconceptions in Mechanics using the FCI
}

\author{
Géraldine Poutot ${ }^{1}$, Bernard Blandin ${ }^{2, *}$ \\ ${ }^{1}$ LIEA, CESI, Assat, France \\ ${ }^{2}$ LIEA, CESI, Montpellier, France \\ *Corresponding author: bblandin@cesi.fr
}

Received January 06, 2015; Revised January 21, 2015; Accepted January 28, 2015

\begin{abstract}
During 3 years, we have used the Force Concept Inventory (FCI) to assess the progress of our First-Year students in Engineering in mastering the concepts of Newtonian Physics and to compare the efficiency of two teaching methods, courses and drills versus Problem-Based Learning. If both methods lead to quite similar deceptive results, the detailed analysis of the response to each question of the test allowed us to identify our students' most common misconceptions. This paper presents this research and discusses our findings.
\end{abstract}

Keywords: newtonian physics, misconceptions in mechanics, testing, force concept inventory

Cite This Article: Géraldine Poutot, and Bernard Blandin, "Exploration of Students' Misconceptions in Mechanics using the FCI." American Journal of Educational Research, vol. 3, no. 2 (2015): 116-120. doi: 10.12691/education-3-2-2.

\section{Introduction}

Beyond the often-reported fact that, to-day, students are not attracted by abstraction or by pure scientific concepts, our First-Year students in Engineering displayed a real disaffection for scientific matters, and particularly for mechanics. In order to reverse this trend, CESI decided to use new teaching methods in Physics, such as ProblemBased learning, which had already been experimented successfully in our School of Informatics. Our intention was to make physics courses more attractive, and we thought that PBL would help our students to acquire the concepts better than through traditional course and drills method. In order to validate this hypothesis, the problems were designed such as to allow the students to reach the same learning objectives as in the courses and drills sessions, and PBL groups were run in parallel with traditional courses during one year. This experiment is presented in Blandin [1]. To measure students' level in mechanics and to compare the outcomes of the two teaching methods, CESI has used for 3 years the Force Concept Inventory (FCI), developed by Hestenes and his colleagues [2] to assess how our students mastered Newtonian Physics fundamental concepts.

This paper presents our students' results at the FCI and our analysis of the misconceptions they commonly made.

\section{Material and Methods}

The FCI is composed of 30 questions, covering six themes: kinematics, Newton's first law, Newton's second law, Newton's third law, principle of action-reaction and kinds of force. In our experiment, each student took the test twice, once before the course in mechanics and once after. Each question is linked to one or several conceptual errors through the proposed answers. The correspondence between answers and conceptual errors is given in a table which was revised by David Hestenes and Jane Jackson in autumn 2007. This table is available on the Arizona State University web site, with the permission of Jane Jackson [3]. The «Newtonian threshold» is considered as attained when the score exceeds $60 \%$ of correct answers, i.e. it is above 17, when each question weights one point.

The programme in Engineering offered by CESI starts two years after the baccalaureate and lasts three years. The FCI test was used in CESI First-Year Course in Mechanics during three successive years as pre-test and post-test, along with more traditional exams. The results of the processing of data collected during school year 2010-2011 were published in G. Poutot\& al. [4]. Concerning the FCI, this first study did not allow concluding that the PBL approach was more efficient than a traditional lesson: these first results showed that, in average, the Newtonian threshold was far from being reached. Whatever was the teaching method, there was no significant difference.



Figure 1. Distribution of notes at the FCI from 2010 to 2013 
During year 2011-2012, only 14 students reached the threshold at the pre-test, and 16 at the post-test. During the three years, 279 notes were above the Newtonian threshold, among 850 pre-test and 957 post-test in all. Figure 1 shows the distribution of the notes for all the 3 years cumulated.

In order to understand the reasons of such a weak level, we decided to deepen the analysis of the FCI results and to analyze the answers question by question.

As signaled by Huffman and Heller [5], the authors of the FCI recommend the use of their test in three cases: firstly, as a diagnostic tool; secondly, for evaluating instruction and finally as a placement exam. In spite of Huffman and Heller criticism, it seemed to us that the inventory could still be used as a diagnostic tool and as a mean to evaluate instruction: Hestenes [2] says that a wrong answer is more significant than a good answer, and the answers were designed to capture misconceptions. Even if the test measures pieces of knowledge rather than a central concept of force [5], we thought that it could provide indications about how our students understand a given situation. Our minimal hypothesis was that the test provided information about their conceptions and misconceptions in Newtonian Mechanics.

Figure 2 shows the percentage of good answers to each question before (pre-test) and after (post-test) the course of mechanics between 2010 and 2013, all students and all teaching methods together.

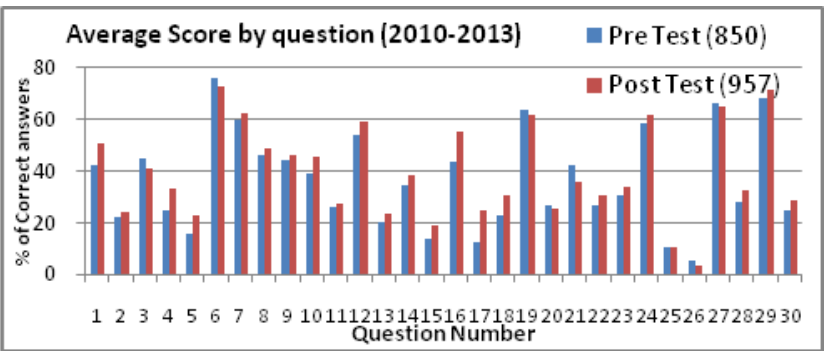

Figure 2. Results of theFCI by question from 2010 to 2013

As the results of the pre-test and of the post-test were very close, which meant that the errors were quite the same before and after the course, we decided to cumulate answers to each question covering all 1807 takes (pre-test and post-test) during the three years before analyzing them in detail. Figure 3 shows the results for all takes cumulated.

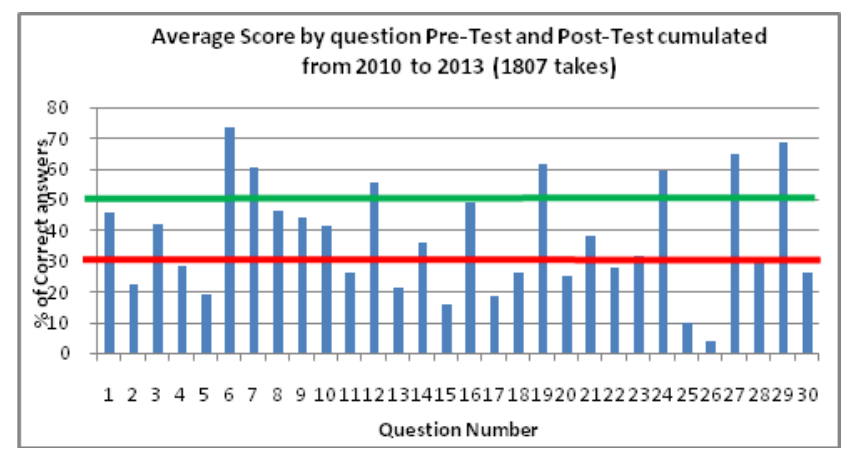

Figure 3. Cumulated Results of the FCI by questions from 2010 to 2013

On figure 3, we have drawn a red and a green line dividing the scores into three subgroups according to the percentage of correct answers. The first group of questions is the one where the score is lower than $30 \%$, the second comprises the questions with scores between 30\% and $50 \%$ and the third group is composed of the questions which got a score above $50 \%$.

\section{Main Results}

\subsection{Analysis of the Answers for Scores Lower than $30 \%$}

Let start with the analysis of the group of questions having got scores under $30 \%$. Include in this group are the questions $n^{\circ} 2,4,5,11,13,15,17,18,20,22,25,26$ and 30 . These are the questions where our students have most difficulties. The table from Hestenes and Jackson [3] mentioned above proposes a list of misconceptions related to each answer for each question.

This will be illustrated by an example. Question 15 read as follows: "a large truck breaks down out on the road and receives a push back into town by a small compact car. Having augmented its speed the car reaches its cruising speed, still pushing the truck" and this text is illustrated by an image showing a small car pushing a big lorry.

Five proposals are made to describe the situation:

A. the amount of force with which the car pushes on the truck is equal to that with which the truck pushes back on the car.

B. the amount of force with which the car pushes on the truck is smaller than that with which the truck pushes back on the car.

C. the amount of force with which the car pushes on the truck is greater than that with which the truck pushes back on the car.

D. the car's engine is running so the car pushes against the truck, but the truck's engine is not running so the truck cannot push back against the car. The truck is pushed forward simply because it is in the way of the car.

E. neither the car nor the truck exert any force on the other. The truck is pushed forward simply because it is in the way of the car.

The correct answer is A (Action - Reaction principle). According to Hestenes\& al. [3], if the student validates the answer $\mathrm{D}$, then he/she makes an error in the identification of active force. If he/she validates answer $\mathrm{C}$ then his/her conception is that the agent the most active produces the biggest force. If he/she validates answer $\mathrm{B}$, the error concerns the influence of the mass on force.

For this question, the percentages of the different answers from our students are represented in Diagram 1.



Diagram 1. Answers to question 15 
We can see that $66.85 \%$ of the respondents make an error on the principle of action-reaction for a system moving at constant speed. For them, the solid which produces the movement has the biggest force while, in fact, the system composed by the truck and the car is in balance (First Newton's law) and while the action-reaction principle applies.

The following table (Table 1) shows the answers made by our students to the questions in this first group with scores under $30 \%$. The correct answer to the question is in green, the yellow represents the highest percentage(s) of answers. Sometimes, two answers have quite similar scores and are considered equally.

The misconceptions provided by Hestenes \& al. [3] which correspond to the highest percentage(s) of errors made by our students are presented in the second table (Table 2).

Table 1. Answers for scores under $\mathbf{3 0 \%}$

\begin{tabular}{|c|c|c|c|c|c|c|}
\hline \multirow{2}{*}{$\begin{array}{c}\text { Question } \\
\mathrm{N}^{\circ}\end{array}$} & \multicolumn{7}{|c|}{ Percentage of answers to the question } \\
\cline { 2 - 7 } & $\mathrm{A}$ & $\mathrm{B}$ & $\mathrm{C}$ & $\mathrm{D}$ & $\mathrm{E}$ & Nothing \\
\hline 2 & 22,86 & 14,22 & 5,53 & 46,15 & 10,02 & 1,22 \\
\hline 4 & 66,69 & 1,60 & 0,89 & 1,49 & 28,83 & 0,50 \\
\hline 5 & 4,43 & 19,37 & 23,85 & 32,21 & 19,37 & 0,77 \\
\hline 11 & 7,19 & 15,72 & 46,21 & 26,62 & 2,66 & 1,60 \\
\hline 13 & 15,55 & 14,61 & 45,71 & 21,91 & 1,00 & 1,22 \\
\hline 15 & 16,44 & 11,29 & 66,85 & 3,27 & 1,00 & 1,16 \\
\hline 17 & 58,05 & 18,82 & 1,66 & 17,54 & 2,93 & 1,00 \\
\hline 18 & 2,66 & 26,51 & 10,40 & 42,22 & 17,10 & 1,11 \\
\hline 20 & 14,39 & 4,98 & 41,51 & 25,84 & 11,95 & 1,33 \\
\hline 22 & 31,65 & 24,46 & 2,66 & 36,97 & 2,88 & 1,38 \\
\hline 25 & 2,43 & 9,24 & 10,46 & 56,39 & 19,92 & 1,55 \\
\hline 26 & 26,40 & 46,10 & 4,21 & 17,04 & 4,26 & 1,99 \\
\hline 30 & 1,94 & 4,43 & 26,51 & 2,99 & 62,65 & 1,49 \\
\hline
\end{tabular}

Table 2. Misconceptions according to Hestenes\& al. for scores under $30 \%$

\begin{tabular}{|c|c|}
\hline $\begin{array}{c}\text { Question } \\
\mathrm{N}^{\circ}\end{array}$ & From table II for the Force Concept Inventory \\
\hline 2 & R1. Mass makes things stop \\
\hline 4 & AR1. Greater mass implies greater force \\
\hline 5 & AF2. Motion implies active force \\
\hline 11 & I1. Impetus supplied by "hit" \\
\hline 13 & I3. Impetus dissipation \\
\hline 15 & AR2. Most active agent produces greatest force \\
\hline 17 & CI1. Largest force determines motion \\
\hline 18 & K2. Velocity-acceleration indiscriminated \\
\hline 20 & AF6. Force causes acceleration to terminal velocity \\
\hline 22 & R2. Motion when force overcomes resistance \\
\hline 25 & R2. Motion when force overcomes resistance \\
& R3. Resistance oppose force/impetus \\
\hline 26 & I1. Impetus supplied by "hit" \\
\hline 30 & Hesternes \\
\hline
\end{tabular}

If we follow Hestenes and his colleagues (misconceptions indicated in Table 2), it seems that there is no dominant conceptual error among our students. But if we look carefully at the phrasing of the answers which have got the highest scores, things change, and we can identify three misconceptions, some of them being recurrent in spite of the type of problem (Table 3).

Out of 13 questions, 8 concern the force applied to a solid in motion. We can make the hypothesis that our students do not correctly understand what is happening when there are several forces applied to a solid in motion. It seems that their recurrent point of failure is that they consider that there must be a force in the direction of the movement: some questions revealed it explicitly, since their favorite answers includes a force in the direction of the movement $(5,11,18)$; others are more implicit: for the students, there is a resulting force in the direction of the movement, even if there are no force applied or if the only forces in presence are action and reaction of two bodies against each other $(13,15,17,25,30)$. Another recurrent misconception is that the weight or the mass has an impact on the trajectory of a falling object $(2,4)$; and a third one reveals confusion between acceleration and velocity (20, 22, 26).

Table 3. Our students' misconceptions (1)

\begin{tabular}{|c|c|}
\hline QuestionN & Students most common misconceptions \\
\hline 2 & Weight matters: the heavier falls nearer \\
\hline 4 & Weight matters: the heavier provides a greater force \\
\hline 5 & There is a force in the direction of the movement \\
\hline 11 & There is a force in the direction of the movement \\
\hline 13 & There is a force in the direction of the movement \\
\hline 15 & The force is in the direction of the movement \\
\hline 17 & The force is bigger in the direction of the movement \\
\hline 18 & There is a force in the direction of the movement \\
\hline 20 & Confusion between acceleration and velocity \\
\hline 25 & Confusion between acceleration and velocity \\
\hline 26 & The force is bigger in the direction of the movement \\
\hline 30 & Confusion between acceleration and velocity \\
\hline
\end{tabular}

These notionsare widely covered by the program through exercises on Newton's first law and third law, and it is the same for the principle of action-reaction. If the students make a mistake concerning these mechanical concepts before the course, it could be considered as normal, because many of them are not familiar with mechanics. But, when they commit these errors after the course, whatever the teaching method used, it becomes problematic, and this raises a lot of questions!

\subsection{Analysis of the Answers for Scores between $30 \%$ and $50 \%$}

Questions for which the score is between $30 \%$ and $50 \%$ are $n^{\circ} 1,3,8,9,10,14,16,21,23$ and 28. The answers are presented with the same color convention as before in Table 4 below.

Table 4. Answers for scores between $30 \%$ and $50 \%$

\begin{tabular}{|c|c|c|c|c|c|c|}
\hline \multirow{2}{*}{$\begin{array}{c}\text { Question } \\
\mathrm{N}^{\circ}\end{array}$} & \multicolumn{7}{|c|}{ Percentage of answers to the question } \\
\cline { 2 - 7 } & $\mathrm{A}$ & $\mathrm{B}$ & $\mathrm{C}$ & $\mathrm{D}$ & $\mathrm{E}$ & Nothing \\
\hline 1 & 21,36 & 5,59 & 46,32 & 17,60 & 8,80 & 0,33 \\
\hline 3 & 36,47 & 13,23 & 42,34 & 2,21 & 5,04 & 0,72 \\
\hline 8 & 22,36 & 47,04 & 2,05 & 7,64 & 19,92 & 1,00 \\
\hline 9 & 3,49 & 19,59 & 22,36 & 8,63 & 44,77 & 1,16 \\
\hline 10 & 42,17 & 2,27 & 15,27 & 28,33 & 10,74 & 1,22 \\
\hline 14 & 35,75 & 17,54 & 8,63 & 36,30 & 0,89 & 0,89 \\
\hline 16 & 49,47 & 2,49 & 40,45 & 3,27 & 3,38 & 0,94 \\
\hline 21 & 8,47 & 14,78 & 23,80 & 12,73 & 38,63 & 1,60 \\
\hline 23 & 12,84 & 32,21 & 22,14 & 26,07 & 5,04 & 1,72 \\
\hline 28 & 1,27 & 4,32 & 11,12 & 51,63 & 30,16 & 1,49 \\
\hline
\end{tabular}

Table 5. Misconceptions according to Hestenes\& al. for scores between $30 \%$ and $50 \%$

\begin{tabular}{|c|c|}
\hline $\begin{array}{c}\text { Question } \\
\mathrm{N}^{\circ}\end{array}$ & From table II for the Force Concept Inventory \\
\hline 1 & G3. Heavier objects fall faster \\
\hline 3 & AF6. Force causes acceleration to terminal velocity \\
\hline 8 & CI3. Last force to act determines motion \\
\hline 9 & CI3. Last force to act determines motion \\
\hline 10 & I4. Gradual/delayed impetus build-up \\
\hline 14 & K4. Ego-centered reference frame \\
\hline 16 & AR2. Most active agent produces greatest force \\
\hline 21 & CI3. Last force to act determines motion \\
\hline 23 & I3. Impetus dissipation \\
\hline 28 & AR1. Greater mass implies greater force \\
\hline
\end{tabular}


Then, we compare the results of the students with the misconceptions provided by Hestenes\& al. [3] (Table 5). When two wrong answers have similar scores (i.e. within an interval lower than 5\%), we consider them equally.

In Table 5, we see that one misconception "the last force to act determines motion" appears more often than others, and that the other errors just appear once. This misconception is part of the one identified previously: the movement is driven by the last force applied.

Again, if we look carefully at the answers which have got the highest scores, we can identify three misconceptions already spotted in the previous set of questions, together with a new one (Table 6).

Table 6. Our students' misconceptions (2)

\begin{tabular}{|c|c|}
\hline Question $\mathbf{N}^{\circ}$ & Students most common misconceptions \\
\hline 1 & Weight matters: the heavier falls quicker \\
\hline 3 & Confusion between acceleration and velocity \\
\hline 8 & $\begin{array}{c}\text { The motion changes in the direction of the force } \\
\text { impacting the object }\end{array}$ \\
\hline 9 & $\begin{array}{c}\text { Velocity considered as a number and not as a vector } \\
\text { The motion changes in the direction of the force } \\
\text { impacting the object }\end{array}$ \\
\hline 10 & Confusion between acceleration and velocity \\
\hline 14 & $\begin{array}{c}\text { Fall from a moving object implies an initial velocity at } \\
\text { the opposite of the movement }\end{array}$ \\
\hline 21 & The force is in the direction of the movement \\
\hline 23 & Confusion between acceleration and velocity \\
\hline 28 & $\begin{array}{c}\text { The motion is in the direction of the force } \\
\text { Confusion between acceleration and velocity }\end{array}$ \\
\hline
\end{tabular}

The same misconceptions as in the previous set are the following: weight or mass have an impact on the trajectory of a falling object (1) or on the intensity of the force (28); some confusion between acceleration and velocity $(3,10,21,23-2)$ is still influencing the answers, and finally, the idea that there is a driving force in the direction of the movement of an object is again underpinning the answers to several questions (8, 9-2, 16, 23-1). It seems that there is also a misconception related to the vector nature of velocity, which causes wrong answers to questions 9(a) and $14 \ldots$

\subsection{Analysis of the Answers in the Upper Part (Score above 50\%)}

Table 7. Answers for scores over $\mathbf{5 0 \%}$

\begin{tabular}{|c|c|c|c|c|c|c|}
\hline $\begin{array}{c}\text { Question } \\
\mathrm{N}^{\circ}\end{array}$ & \multicolumn{6}{|c|}{ Breaking down of answers in \% } \\
\cline { 2 - 7 } & $\mathrm{A}$ & $\mathrm{B}$ & $\mathrm{C}$ & $\mathrm{D}$ & $\mathrm{E}$ & Nothing \\
\hline 6 & 16,77 & 73,88 & 5,59 & 1,72 & 1,27 & 0,77 \\
\hline 7 & 10,96 & 60,99 & 13,72 & 4,32 & 9,41 & 0,61 \\
\hline 12 & 1,00 & 56,06 & 33,98 & 5,64 & 2,10 & 1,22 \\
\hline 19 & 16,49 & 3,10 & 4,10 & 13,00 & 61,98 & 1,33 \\
\hline 24 & 59,66 & 3,15 & 22,03 & 5,20 & 8,47 & 1,49 \\
\hline 27 & 18,87 & 9,57 & 65,36 & 1,99 & 2,27 & 1,94 \\
\hline 29 & 5,09 & 69,34 & 2,27 & 20,64 & 1,00 & 1,66 \\
\hline
\end{tabular}

Table 8. Misconceptions according to Hestenes \& al. for scores over $\mathbf{5 0 \%}$

\begin{tabular}{|c|c|}
\hline Question $\mathrm{N}^{\circ}$ & From table II for the Force Concept Inventory \\
\hline 6 & I5. Circular impetus \\
\hline 7 & CF. Centrifugal force \\
\hline 12 & I3.Impetus dissipation \\
\hline 19 & K2. Velocity-acceleration indiscriminated \\
\hline 24 & I3.Impetus dissipation \\
\hline 27 & R1. Mass makes things stop \\
\hline 29 & G1. Air pressure-assisted gravity \\
\hline
\end{tabular}

Questions getting scores over $50 \%$ are $n^{\circ} 6,7,12,19$, 24, 27 and 29. The answers to these questions are presented in Table 7 . There are still significant percentages of wrong answers to these questions, so we can repeat the same exercise as before applied to these questions (Table 8), taking into consideration the highest score(s) among the wrong answers.

Again, there is no dominant misconception appearing in Table 8. But, if we do the same exercise as previously, we can identify from their responses some misconceptions, which are presented in Table 9 below.

\begin{tabular}{|c|c|}
\hline $\begin{array}{l}\text { Question } \\
\mathrm{N}^{\circ}\end{array}$ & Students most common misconceptions \\
\hline 6 & $\begin{array}{l}\text { The object keeps its trajectory according to the initial } \\
\text { impulsion }\end{array}$ \\
\hline 7 & $\begin{array}{c}\text { The object keeps its trajectory according to the initial } \\
\text { impulsion } \\
\text { The motion changes in the direction of the force impacting } \\
\text { the object (centrifugal force) }\end{array}$ \\
\hline 12 & The motion is in the direction given by the initial impulsion \\
\hline 19 & $\begin{array}{l}\text { Confusion between acceleration and velocity } \\
\text { Confusion between position and velocity }\end{array}$ \\
\hline 24 & Confusion between acceleration and velocity \\
\hline 27 & The movement stops if the force stops \\
\hline 29 & Air pressure assists gravity \\
\hline
\end{tabular}

Again, we find in Table 9 misconceptions already mentioned previously: confusion between acceleration and velocity $(19-1,24)$, the idea that a movement is caused by a force in the same direction (7-2, 27). Another misconception, which is closed to the latter, is that the trajectory of an object is given by the direction or "the form" of the last impulsion $(6,7-1,12)$. Finally, we also find that some students make confusion between the velocity and the position of an object on a representation of the trajectory as a function of time (19-2).

\section{Discussion}

The study of Lasry\& al. [6] warns us: the FCI test is consistent by itself, but nonetheless, individual responses may not be reliable. These authors noted that, in their experiment, $31 \%$ of all answers were changed between the first and the second take of the test. On the total number of changed answers, $13 \%$ did not affect the score, $8 \%$ diminished it and $10 \%$ augmented the score. But since we have decided to cumulate the different takes in order to analyze most frequent misconceptions and not individual results, this problem of reliability disappears.

Our research shows that the FCI can be at the same time a good metric for individual learning and a good indicator of misconceptions if we analyze in detail the answers to questions: we have been able to identify misconceptions which appear to be widely shared among our students.

A research in some databases listing misconceptions in physics shows that the ones identified among our students have already been identified by other researchers:

"The motion of an object is always in the direction of the net force applied to the object": this misconception appears in the list compiled by the Operation Physics Elementary / Middle School Physics Education Outreach project of the American Institute of Physics [7]. "The net force must be in the direction of motion, so objects will travel along a line in that direction" is another phrasing of the same misconception which has been proposed in a list provided online by the University of Montana [8], quoting 
as references Halloun\&Hestenes [9], Gunstone [10] and Aguirre [11].

"Confusion between acceleration and velocity": this misconception is again identified in the list of the American Institute of Physics [7] and also, with a slightly different formulation, by Trowbridge \& McDermott [12].

"Large objects exert a greater force than small objects": this misconception also appears in the list of the American Institute of Physics [7]. Another phrasing, "Heavier objects fall faster than light objects", revealing the same misconception which we have identified as "the mass matters" is given in the list of the University of Montana [8], and the reference is attributed, again, to Halloun and Hestenes [9].

"Confusion between velocity and position of the object": this misconception is also identified in the list from the University of Montana [8], and the reference is attributed to McDermott \&al. [13].

The trajectory of an object is given by the direction or "the form" of the last impulsion: this misconception is given under a slightly different phrasing "Objects can be trained to follow a certain path by forces, and will continue along that path, even after the forces are removed" in the list from the University of Montana [8], and comes from Halloun and Hestenes [9] and also from Caramazza\& al. [14].

It appears that many of our students' misconceptions are quite widely spread. The only difference is that the misconceptions described by other researchers were identified among children. Our students are no longer children. They are between 20 and 24 years old, but they also convey the same conceptual difficulties as children, and furthermore, for a majority of them, these misconceptions are not changed to Newtonian conceptions after the course, as shown by Figure 2. This persistence seems to be independent of the teaching method which is used, since there was no significant difference appearing between the students who attended traditional course and drills sessions and those having attended Problem-Based Learning sessions with the same programme in Mechanics during the 3 years of our experiment $[4,15]$.

\section{Conclusion}

Our research shows, at this stage, that our students still have prescientific conceptions of the basic phenomenons described by the Newtonian Mechanics, and that these prescientific conceptions operate as "epistemological obstacles" [16], preventing them to acquire scientific conceptions. Our next objective is to take these obstacles into consideration, not so much as obstacles the students will have to jump over, but as "threshold concepts" [17], [18], i.e., as sorts of portals, potentially opening up a new and previously inaccessible way of thinking about Mechanics.

It means that we will also have to identify the "keys" able to open these portals [19], i.e. the notions and the pedagogy which will allow the students to open the "liminal state" for understanding the phenomenons in Newtonian terms. Our hypothesis is that only projects, which allow creating links between the key-notions, are likely to facilitate such learning. This is why our next step will be to design and implement Project-Based Learning.

\section{References}

[1] Blandin B. (2010), Learning Physics: a Competency-based Curriculum using Modelling Techniques and PBL Approach. Oral presentation at the GIREP - ICPE-MPTL International Conference, Reims 22-27 August 2010. [Online], accessed 201210-02, at http://www.univ-reims.fr/site/evenement/girep-icpemptl-2010-reims-internationalconference/gallery_files/site/1/90/4401/22908/29321/29590.pdf

[2] Hestenes, D., Wells, M., and Swackhamer, G. (1992). Force Concept Inventory, The Physics Teacher 30, 141-151

[3] Hestenes, D. \& Jackson, J. (2007) Table II for the Force Concept Inventory (revised form 081695R) [online] accessed 2013-11-03 at http://modeling.asu.edu/R\&E/FCI-RevisedTable-II_2010.pdf (a password is needed)

[4] Poutot, G., Bacila, A., Ageorges, P., Blandin, B. (2012). PBL in Mechanics: some results of a controlled experiment, in Proceedings of the World Conference in Physics Education, Istanbul, Turkey, July, 1st - 6th, 2012, p. 405-412. [Online] downloaded from http://www.wcpe2012.org/proceedings.htmlon 2014-03-01.

[5] Huffman, D. and Heller, P. (1995), What does the Force Concept Inventory Actually Measure? The Physics Teacher 33, 138-143.

[6] Lasry, N., Rosenfield, S., Dedic, H., Dahan A. and Reshef, O. (2011) The puzzling reliability of the force Concept Inventory, The American Journal of Physic 79, 909-912.

[7] Children's misconceptions about Science. [online] downloaded from the following URL: http://amasci.com/miscon/opphys.html on 2014-11-25

[8] URL: http://www.physics.montana.edu/physed/misconceptions/, accessed on 2014-11-25

[9] Halloun I. A. and Hestenes D. (1985) Common-sense concepts about motion, in Am. J. Phys. 53, 1056-1065.

[10] Gunstone R. F. (1987) Student understanding in mechanics: A large population survey, in Am. J. Phys. 55, 691-696

[11] Aguirre J.M. (1988) Student preconceptions about vector kinematics, in Phys. Teach. 26, 212-216

[12] Trowbridge D.E. and McDermott L. C. (1981) Investigation of student understanding of the concept of acceleration in one dimension, in Am. J. Phys. 49, 242-253

[13] McDermott L.C., Rosenquist M.L. and van Zee E.H. (1987) Student difficulties in connecting graphs and physics: Examples from kinematics, in Am. J. Phys., 55, 503-513.

[14] Caramazza A., McCloskey, M. and Green, B. (1981) Naive beliefs in "sophisticated" subjects: misconceptions about trajectories of objects, in Cognition 9, 117-123

[15] Blandin, B. Ageorges, P. Bacila, A. Poutot, G. (2013) Mise en œuvre de l'approche par problèmes dans une école d'ingénieurs: effets cognitifs et conatifs, in Actes du congrès de l'Actualité de la Recherche en Éducation et Formation (AREF - AECSE), Laboratoire LIRDEF - EA 3749 - Universités de Montpellier, Août 2013 [en ligne] http://www.aref2013.univmontp2.fr/cod6/?q=content/176-mise-en-\%C5\%93uvre-de1\%E2\%80\%99approche-par-probl\%C3\%A8mes-dans-une\%C3\%A9cole-d\%E2\%80\%99ing\%C3\%A9nieurs-effet-cognitifs-0

[16] Bachelard, G. (1938) La Formation de l'esprit scientifique. Contribution à une psychanalyse de la connaissance objective, Paris, Vrin.

[17] Meyer, J.H.F. and Land, R. (2003) Threshold concepts and troublesome knowledge (1): linkages to ways of thinking and practising, in Rust, C. (ed.), Improving Student Learning - ten years on. Oxford: OCSLD

[18] Meyer, J.H.F. and Land, R. (2005) Threshold concepts and troublesome knowledge (2): Epistemological considerations and a conceptual framework for teaching and learning, in Higher Education 49: 373-388

[19] Carstensen, A.-K., Bernhard, J. (2007) Threshold Concepts and Keys to the Portal of Understanding. Some Examples from Electrical Engineering, in Land, R., Meyer, J.H.F. \& Smith, J. (eds.) Threshold Concepts within the Disciplines, Rotterdam: Sense Publishers, 143-154. 